\title{
METABOLIC RESPONSE TO SUBACUTE AND SUBCHRONIC IRON OVERLOAD IN A RAT MODEL
}

\author{
Khadiga G. Adham, ${ }^{1,2 *}$ Manal H. Farhood, ${ }^{1}$ Maha H. Daghestani, ${ }^{1}$ \\ Nadia A. Aleisa, ${ }^{1}$ Ahlam A. Alkhalifa, ${ }^{1}$ Maha H. El Amin, ${ }^{1}$ Promy Virk, ${ }^{1}$ \\ Mai A. Al-Obeid ${ }^{1}$ and Eman M. H. Al-Humaidhi ${ }^{3}$ \\ 'Zoology Department, College of Science, King Saud University, Ryadh, Saudi Arabia \\ ${ }^{2}$ Zoology Department, College of Science, Alexandria University, Alexandria, Egypt \\ ${ }_{3}^{3}$ Princess Nora Bint Abdul Rahman University, Ryadh, Saudi Arabia
}

(Received: February 18, 2015; accepted: May 18, 2015)

\begin{abstract}
One of the common causes of iron overload is excessive iron intake in cases of iron-poor anemia, where iron saccharate complex (ISC) is routinely used to optimize erythropoiesis. However, non-standardized ISC administration could entail the risk of iron overload. To induce iron overload, Wistar rats were intraperitoneally injected with subacute $\left(0.2 \mathrm{mg} \mathrm{kg}^{-1}\right)$ and subchronic $\left(0.1 \mathrm{mg} \mathrm{kg}^{-1}\right)$ overdoses of ISC for 2 and 4 weeks, respectively. Iron status was displayed by an increase in transferrin saturation (up to $332 \%$ ) and serum and liver iron burden (up to $19.3 \mu \mathrm{mol} \mathrm{L}^{-1}$ and $13.2 \mu \mathrm{mol} \mathrm{g}^{-1}$ wet tissue, respectively) together with a drop in total and unsaturated iron binding capacities "TIBC, UIBC" as surrogate markers of transferrin activity. Iron-induced leukocytosis (up to 140\%), along with the decline in serum transferrin markers (up to $43 \%$ ), respectively, mark positive and negative acute phase reactions. Chemical stress was demonstrated by a significant rise $(\mathrm{p}>0.05)$ in indices of the hemogram (erythrocytes, hemoglobin, hematocrit, leukocytes) and stress metabolites [corticosterone (CORT) and lactate]. Yet, potential causes of the unexpected decline in serum activities of ALT, AST and LDH $(p>0.05)$ might include decreased hepatocellular enzyme production and/or inhibition or reduction of the enzyme activities. The current findings highlight the toxic role of elevated serum and liver iron in initiating erythropoiesis and acute phase reactions, modifying iron status and animal organ function, changing energy metabolism and bringing about accelerated glycolysis and impaired lactate clearance supposedly by decreasing anaerobic threshold and causing premature entering to the anaerobic system.
\end{abstract}

Keywords: Iron overload - iron status - acute phase reactions - organ function enzymes - chemical stress indicators

\section{INTRODUCTION}

Iron supplements are used to treat states of increased requirements for erythropoetinstimulated red blood cell production. In case of iron overload, non-transferrin-bound iron eventually gets internalized into tissues because of the lack of regulating mechanisms of iron excretion from the circulation [6]. Serum iron, total iron binding capacity (TIBC), unsaturated iron binding capacity (UIBC) and percent transferrin saturation are related indices that are routinely measured to assess the iron status of an animal and are widely used for the diagnosis of iron overload.

\footnotetext{
*Corresponding author; e-mail addresses: kadham@ksu.edu.sa, kadham_100@yahoo.com
} 
The liver is at particular risk from iron-induced functional damage given that iron saturates the liver first before accumulating in other organs $[6,14]$. Aspartate and alanine aminotransferases (AST and ALT, respectively) and lactate dehydrogenase (LDH) are enzymes released in serum in cases of hepatocellular injury [20]. Complete blood count $(\mathrm{CBC})$ estimates primary and secondary medical conditions that affect the blood and bone marrow [8]. The stress hormone CORT is the principal glucocorticoid involved in the regulation of stress responses in many species including rodents [21]. CORT in the blood is mostly unbound and can usually be demonstrated after few minutes, which makes plasma CORT a useful parameter for measurement of acute stress [27]. Lactate is another main effector in rodent stress system that helps organisms survive stressful situations [4].

Iron isomaltoside (Monofer ${ }^{\circledR}$ ) is another new dextran-free parenteral iron product that is currently approved and is being marketed in several countries. However comparing this product with ISC, Toblli et al. [29] found that the iron isomaltoside caused more adverse effects in terms of biochemistry, oxidative stress, inflammatory markers and iron deposition in the liver, heart and kidneys of healthy rats than did ISC. But still excessive intake of ISC poses significant toxicity [6], which is very often, overlooked in the fervor to correct anemia by giving these iron supplements. Current studies suggest that the recommended clinical iron dosage has to be revised sharply downward and that more studies have to be conducted to analyze the potential of human and animal ability to safely handle the stress of supplemental iron. Therefore, we herein recruited ISC as an iron supplement to induce iron overload based on earlier reports on LD50 dosage in murine species. We examined the physiological changes elicited in male Wistar rat in response to subacute and subchronic intraperitonial ISC overdoses. The objective of this study is to assess effects imposed upon the animal due to iron overload and to evaluate the animal's iron status and the overall physiological health and functional competence.

\section{MATERIALS AND METHODS}

\section{Drug}

Iron saccharate complex (ISC) (Ferosac ${ }^{\circledR}$, manufactured by SPIMACO, Saudi Pharmaceutical Industries and Medical Appliances Corporation, Saudi Arabia). The ISC formula does not contain dextran and has demonstrated a low incidence of adverse effects.

\section{Experimental animal and group allocation}

A total number of 40 adult male Wistar albino rat, Rattus norvegicus, weighing 150-180 g, was obtained from the animal house facility, King Saud University. In the lab, animals were housed in stainless steel rat cages (two per cage to avoid isolation 
or overcrowding) under standard laboratory conditions (temperature, $24 \pm 3{ }^{\circ} \mathrm{C}$; humidity, $40-60 \%$ ) with a 12-h light-dark cycle. Throughout the experimental duration, rats were given ad libitum access to tap water and commercially available rodent pelleted chow. After one week of acclimation, rats were randomly assigned into four groups, each of which $(\mathrm{n}=10)$ received the specified dosage as an intraperitoneal injection. All rat groups received a daily dose of the specified treatment and were weighed twice a week. Rats of two control groups were injected with an isotonic saline solution $(0.9 \% \mathrm{NaCl})$ over a period of 2 weeks $(\mathrm{C} 1)$ or 4 weeks $(\mathrm{C} 2)$. Animals of the Fe-subchronically and subacutely treated groups received ISC (100 mg Fe $5 \mathrm{ml}^{-1}$, Spimaco, Riyadh, KSA) in two dosages of 0.1 and $0.2 \mathrm{mg}$ elemental iron $/ \mathrm{kg}$ body weight over a period of 4 weeks and 2 weeks, respectively. The subacute and subchronic groups were compared to $\mathrm{C} 1$ and $\mathrm{C} 2$, respectively. The current $\mathrm{Fe}$ doses were based on earlier repeat-dose studies suggesting that iron dextran has a low toxicity and that LD50 in mice is $>2500 \mathrm{mg}$ iron $/ \mathrm{kg}$ [12]. Animal experiments were conducted in accordance with the guidelines of the National Committee for Medical and Bio-ethics, PO Box 6086, 11442, Riyadh, Saudi Arabia and the policy and standard guidelines for ethical conduct in the care and use of nonhuman animals in research [15].

\section{Blood sampling and preparation for analysis}

At the end of the experimental period, animals were anesthetized by inhalation of $\mathrm{CO}_{2}$. Blood samples were obtained from the retro-orbital venous plexus using a capillary pipette method [30], in which blood is allowed to flow by capillary action into a microhematocrit capillary tube. During handling procedures, blood samples were maintained at $5{ }^{\circ} \mathrm{C}$. From each rat, two blood samples were withdrawn, one for whole blood analysis and the second for serum analysis. Blood samples allocated for whole blood analysis were stored in commercially available anticoagulant-treated tubes (EDTA-coated) and kept at $-20{ }^{\circ} \mathrm{C}$ pending rapid blood count.

Blood samples allocated for serum analysis were stored in sterile closed non-heparinized tubes and left undisturbed to clot for $30 \mathrm{~min}$ at room temperature. The clot was then gently rotated with a wooden applicator and samples were centrifuged (Macro Biofuge Stratos centrifuge, Heraeus instruments, Germany) at $1400 \times g$ for 15 min. The clear supernatant serum was aspirated using a Pasteur pipette and apportioned into $0.5 \mathrm{ml}$ aliquots into sterile serum tubes. Tubes were then snap-frozen and stored in liquid nitrogen at $-70{ }^{\circ} \mathrm{C}$ pending analysis. All blood analysis was done in laboratory within $24 \mathrm{~h}$, whereas serum lactate was performed immediately within 30 minutes of collection. 


\section{Quantification of blood indices}

Whole blood was analyzed for the selected indices using a Beckman Coulter LH 750 Hematology Analyzer (Fullerton, CA, USA). In non-hemolyzed serum, TIBC, AST, ALT, LDH, CORT and lactate were determined spectrophotometrically with commercial assay kits. Serum iron concentration was detected using atomic absorption spectroscopy (Varian Chrompack International, Australia). The Dade Behring Dimension RXL MAX chemistry analyzer (Deerfield, IL 60015, USA) was used to determine AST, ALT, LDH, TIBC and lactate; whereas CORT was determined using Victor ${ }^{\mathrm{TM}} 21420$ multilabel counter plate reader for photometry (Perkin Elmer Wallac, Turku, Finland).

Serum iron, AST, ALT, LDH and CORT were determined using commercially available kits (Siemens Healthcare Diagnostics Ltd., Camberly, Surrey, UK). Serum iron concentration was determined according to ICSH [16] at a wavelength of 562 $\mathrm{nm}$. Serum TIBC was measured spectrophotometrically [17] at a wavelength $520 \mathrm{~nm}$. Unsaturated iron binding capacity (UIBC) is calculated by subtracting the serum iron from the TIBC. Percent transferrin saturation is calculated using values of serum iron and TIBC $(\%$ transferrin saturation $=100 \times$ serum iron/TIBC $)$. Serum AST and ALT were assayed colorimetrically [24] at $340 \mathrm{~nm}$. Serum LDH was assayed according to Babson and Babson [3] at $340 \mathrm{~nm}$. Total serum CORT was quantified according to Al-Dujaili et al. [2] using the commercially available Coat-A-Count rat CORT radioimmunoassay kit (Siemens Medical Solutions Diagnostics, Los Angeles, CA, USA) as per the manufacturer's instructions. Quantitative determination of D-lactate (D-lactic acid) was performed in serum using the colorimetric D-lactate assay kit (Eton Bioscience, San Diego, CA) at $490 \mathrm{~nm}$ according to the manufacturer's instructions.

\section{Determination of hepatic iron}

Immediately after blood sampling, animals were sacrificed and livers were excised and cut into small pieces, placed in borosilicate tubes, and stored at $-80{ }^{\circ} \mathrm{C}$ until later used. Thawed liver material was digested in $7 \mathrm{ml}$ of $\mathrm{HNO}_{3} 65 \%$ and $1 \mathrm{ml} \mathrm{H}_{2} \mathrm{O}_{2} 30 \%$ by a closed-vessel microwave wet digestion method method [19] for the metal determination [33] using atomic absorption spectroscopy (Varian Chrompack International, Australia).

\section{Data processing}

Results were expressed as mean \pm standard error (SE). Comparisons of data of experimental groups with the control group were performed with unpaired $t$-test (student's $t$-test) using GraphPad Prism software (GraphPad Software, Inc. La Jolla, CA). Differences at $\mathrm{p}<0.05$ were considered significant. 


\section{RESULTS}

\section{Effects of iron overload on hepatic iron accumulation}

Liver mean iron concentration in rats was obviously higher in both subacutely $(\mathrm{p}>0.01)$ and subchronically $(\mathrm{p}>0.001)$ treated groups $(7.20 \pm 0.79$ and $13.19 \pm 0.97$ $\mu \mathrm{mol} \mathrm{g}{ }^{-1}$ fresh tissue, respectively) than corresponding control subjects $(2.04 \pm 0.34$ and $2.12 \pm 0.36 \mu \mathrm{mol} \mathrm{g}^{-1}$ fresh tissue, respectively) (Table 1). Iron burden in liver was elevated in subchronic group by $354 \%$. Even more, iron concentration in hepatic tissue of rats in subacute group grew by $621 \%$ above control. Concisely, a lower subchronic dose $\left(0.1 \mathrm{mg} \mathrm{kg}^{-1}\right)$ given over a longer period (4 weeks) showed more profound hepatic iron burden than a higher subacute dose $\left(0.2 \mathrm{mg} \mathrm{kg}^{-1}\right)$ given over a shorter period ( 2 weeks).

\section{Effects of iron overload on components of the CBC and serum enzymes and metabolites}

Iron overdose was accompanied by a general significant $(p>0.05)$ increase in all blood cell indices versus control subjects (Fig. 1). Mean values for count of RBCs for the groups subacute, subchronic and their two respective controls were $7.97 \pm 0.8$, $7.76 \pm 0.9,6.20 \pm 0.6$ and $6.40 \pm 0.5 \times 10^{3} \mu \mathrm{L}^{-1}$, respectively. Those for HCT were $44.89 \pm 3.9,44.2 \pm 5.1,38.1 \pm 4.1$ and $37.8 \pm 3.9 \%$, respectively. For $\mathrm{Hb}$, the values were $15.38 \pm 1.21,15.3 \pm 1.1,13.73 \pm 0.9$ and $13.9 \pm 1.0 \mathrm{~g} \mathrm{dL}^{-1}$, respectively. Mean values for total WBC count were $16.4 \pm 1.3,13.72 \pm 1.2,11.73 \pm 0.9$ and $12.0 \pm 1.1 \times$ $10^{3} \mu \mathrm{L}^{-1}$, respectively). TIBC and UIBC of subacute and subchronic groups showed a significant $(p>0.05)$ drop compared to control levels (Table 1) drawing a negative correlation with the significant increase reported for iron accumulation in the liver

Table 1

Effects of iron overload on iron status in male albino rat

\begin{tabular}{|l|c|c|c|c|}
\hline & C1 & Subacute & C2 & Subchronic \\
\hline Hepatic iron & $2.035 \pm 0.357$ & $7.197 \pm 0.786^{* *}$ & $2.121 \pm 0.364$ & $13.186 \pm 0.973^{* * *}$ \\
\hline TIBC & $81.610 \pm 6.195$ & $66.610 \pm 8.385^{*}$ & $80.770 \pm 5.645$ & $60.9 \pm 8.195^{*}$ \\
\hline Serum iron & $7.2 \pm 0.81$ & $15.5 \pm 1.7^{*}$ & $7.7 \pm 0.76$ & $19.3 \pm 2.1^{*}$ \\
\hline UIBC & $72.5 \pm 7.9$ & $54.3 \pm 6.0^{*}$ & $74.5 \pm 8.3$ & $42.7 \pm 5.1^{*}$ \\
\hline$\%$ TS & $9.2 \pm 0.97$ & $24.3 \pm 2.9^{*}$ & $8.8 \pm 0.9$ & $29.2 \pm 3.5 *$ \\
\hline$\%$ increase TS & & 264 & & 332 \\
\hline
\end{tabular}

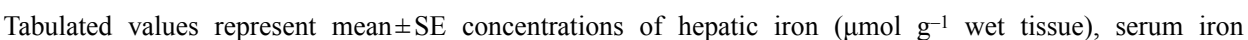
$(\mu \mathrm{mol} \mathrm{L}-1)$, TIBC $(\mu \mathrm{mol} \mathrm{L}-1)$, UIBC $\left(\mu \mathrm{mol} \mathrm{L}{ }^{-1}\right)$ of rats intraperitoneally injected with subacute $\left(0.2 \mathrm{mg} \mathrm{kg}^{-1}\right)$ and subchronic $\left(0.1 \mathrm{mg} \mathrm{kg}^{-1}\right)$ overdoses of ISC for 2 and 4 weeks, respectively. TS stands for transferrin saturation; $\mathrm{C} 1$ and $\mathrm{C} 2$ refer to corresponding controls for subacute and subchronic groups, respectively. Asterisks indicate significant $(* p>0.05)$, highly significant $(* * p>0.01)$ and very highly significant $(* * * p>0.001)$ differences from control values. 

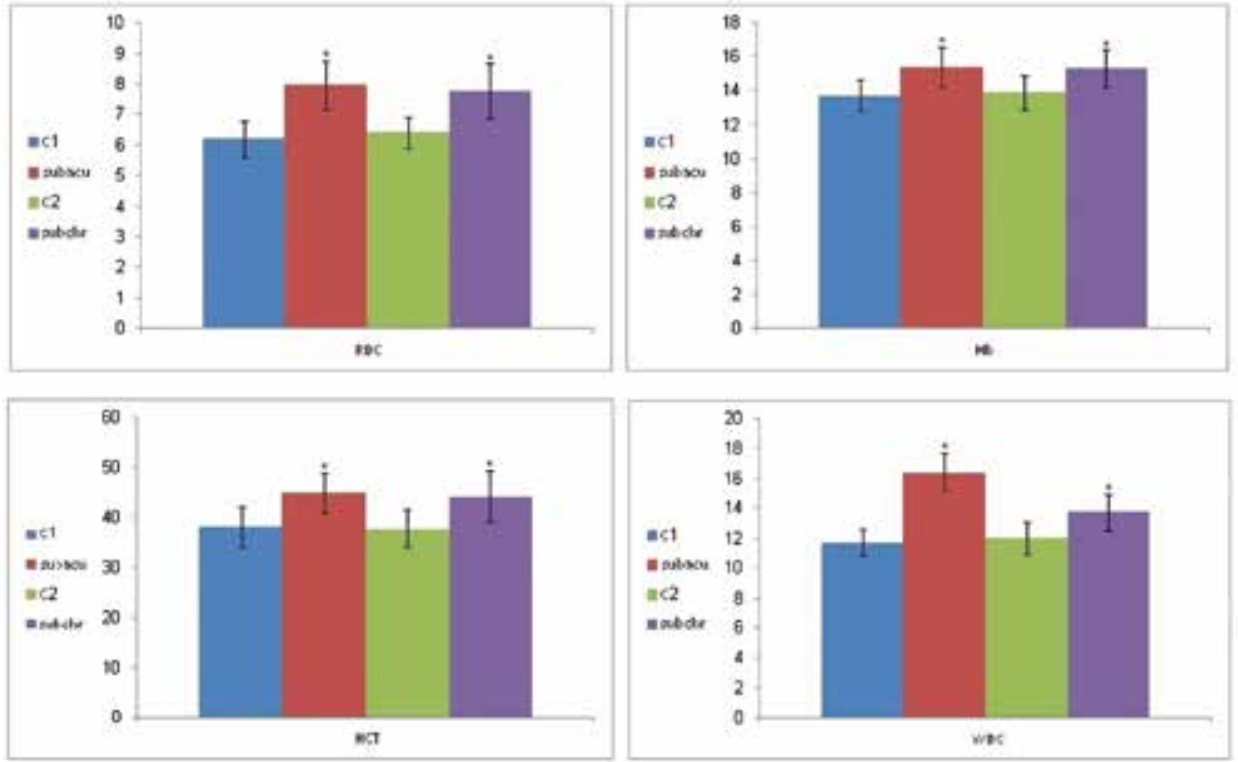

Fig. 1. Effects of iron overload on acute phase reactants in male Wistar rat. Data represent mean $\pm \mathrm{SE}$ blood counts of RBC $\left(\times 10^{3} \mu \mathrm{L}^{-1}\right), \mathrm{Hb}\left(\mathrm{g} \mathrm{dL}^{-1}\right)$, HCT $(\%)$ and WBCs $\left(\times 10^{3} \mu \mathrm{L}^{-1}\right)$ of rats intraperitoneally injected with subacute (Subacu, $0.2 \mathrm{mg} \mathrm{kg}^{-1}$ ) and subchronic (subchr, $0.1 \mathrm{mg} \mathrm{kg}^{-1}$ ) overdoses of ISC for 2 and 4 weeks, respectively. $\mathrm{C} 1$ and $\mathrm{C} 2$ refer to corresponding controls for subacute and subchronic groups, respectively. Asterisks indicate significant $(* p>0.05)$ differences from control values

$(p>0.01-p>0.001)$ and in serum $(p>0.05)$ that amounted to 3.5- and 2.2-fold in subacute and 6.2 and 2.5 in subchronic groups, in a respective order. Also, Table 1 shows 2.7 - and 3.3 -fold increase in \% transferrin saturation in subacute and subchronic groups, respectively.

As a principal glucocorticoid effector of the stress response system in rodents, CORT mean serum concentrations showed a significant $(p>0.05)$ increase in subacute and subchronic rat groups $\left(45.0 \pm 4.9\right.$ and $44.7 \pm 3.8 \mathrm{nmol} \mathrm{L}^{-1}$, respectively) versus control subjects ( $37.8 \pm 4.1$ and $38.1 \pm 3.7 \mathrm{nmol} \mathrm{L}^{-1}$, respectively) (Fig. 2). This was attended by a similar increase $(\mathrm{p}>0.05)$ in the mean circulating level of lactate concentrations in rats subacutely and subchronically injected with $\mathrm{Fe}(8.37 \pm 0.7$ and $7.96 \pm 0.7 \mathrm{mmol} \mathrm{L}^{-1}$, respectively) compared to control rat group $(6.89 \pm 0.5$ and $6.8 \pm 0.4 \mathrm{mmol} \mathrm{L}^{-1}$, respectively).

The common rule governing serum changes of organ function enzymes is a significant $(p>0.05)$ decrease in the activities of AST, ALT and LDH after subacute (118.3, 45.2 and $792.75 \mathrm{UL}^{-1}$, respectively) and subchronic (132.0, 51.0 and 761.38 $\mathrm{UL}^{-1}$, respectively) treatment compared to parallel controls (subacute: 129.2, 62.5 and $834.25 \mathrm{UL}^{-1}$, respectively; subchronic: $133.15,64.0$ and $829.56 \mathrm{UL}^{-1}$, respectively) (Fig. 3, Table 3). 

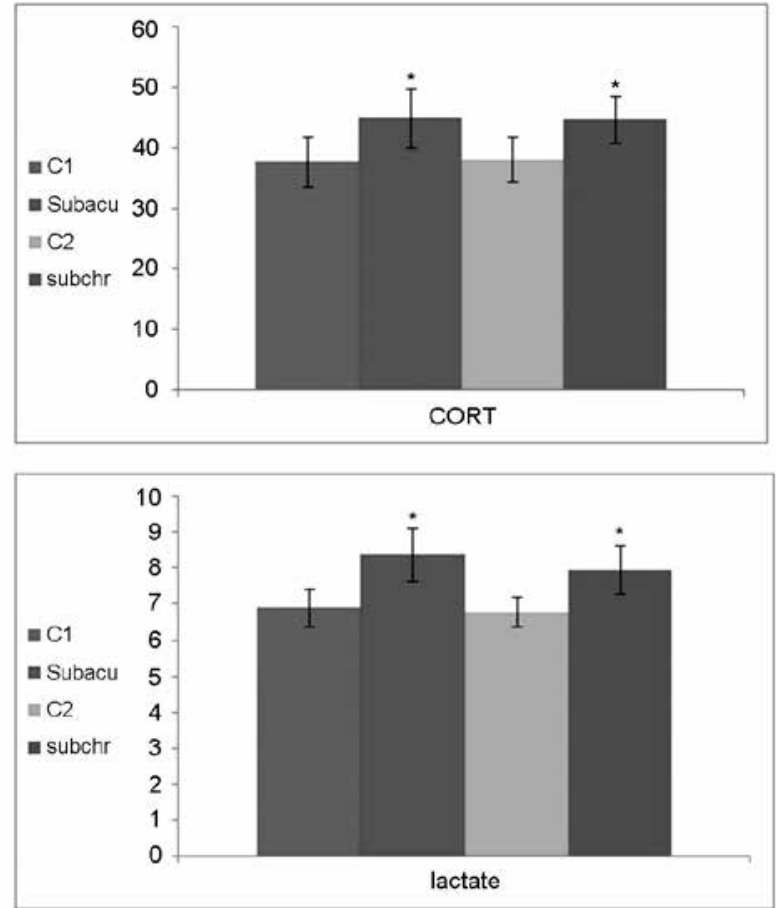

Fig. 2. Effects of iron overload on acute phase reactants in male Wistar rat. Data represent mean \pm SE serum concentrations of CORT $(\mathrm{nmol} \mathrm{L}-1)$ and lactate $\left(\mathrm{mmol} \mathrm{L}^{-1}\right)$ of rats intraperitoneally injected with subacute (Subacu, $0.2 \mathrm{mg} \mathrm{kg}^{-1}$ ) and subchronic (subchr, $0.1 \mathrm{mg} \mathrm{kg}^{-1}$ ) overdoses of ISC for 2 and 4 weeks, respectively. $\mathrm{C} 1$ and $\mathrm{C} 2$ refer to corresponding controls for subacute and subchronic groups, respectively. Asterisks indicate significant $(* \mathrm{p}>0.05)$ differences from control values

Table 2

Effects of iron overload on the induction of serum malondialdehyde (MDA) $(\mu \mathrm{mol} \mathrm{L}-1)$ as a measure of lipid peroxidation and oxidative stress in male albino rat. Tabulated data were reported in an integral part of the current experiment [1]

\begin{tabular}{|c|c|c|c|c|}
\hline \multirow{2}{*}{} & \multicolumn{4}{|c|}{ Groups } \\
\cline { 2 - 5 } & $\mathrm{C} 1$ & Subacute & $\mathrm{C} 2$ & Subchronic \\
\hline MDA & $0.359 \pm 0.05995$ & $1.170 \pm 0.3194 * *$ & $0.410 \pm 0.066$ & $2.120 \pm 0.3544 * * *$ \\
\hline
\end{tabular}

Rats were intraperitoneally injected with subacute $\left(0.2 \mathrm{mg} \mathrm{kg}^{-1}\right)$ and subchronic $\left(0.1 \mathrm{mg} \mathrm{kg}^{-1}\right)$ overdoses of ISC for 2 and 4 weeks, respectively. $\mathrm{C} 1$ and $\mathrm{C} 2$ refer to corresponding controls for subacute and subchronic groups, respectively. Asterisks denote highly $(* * p>0.01)$ and very highly significant $(* * * p 0.001)$ differences from control values. 

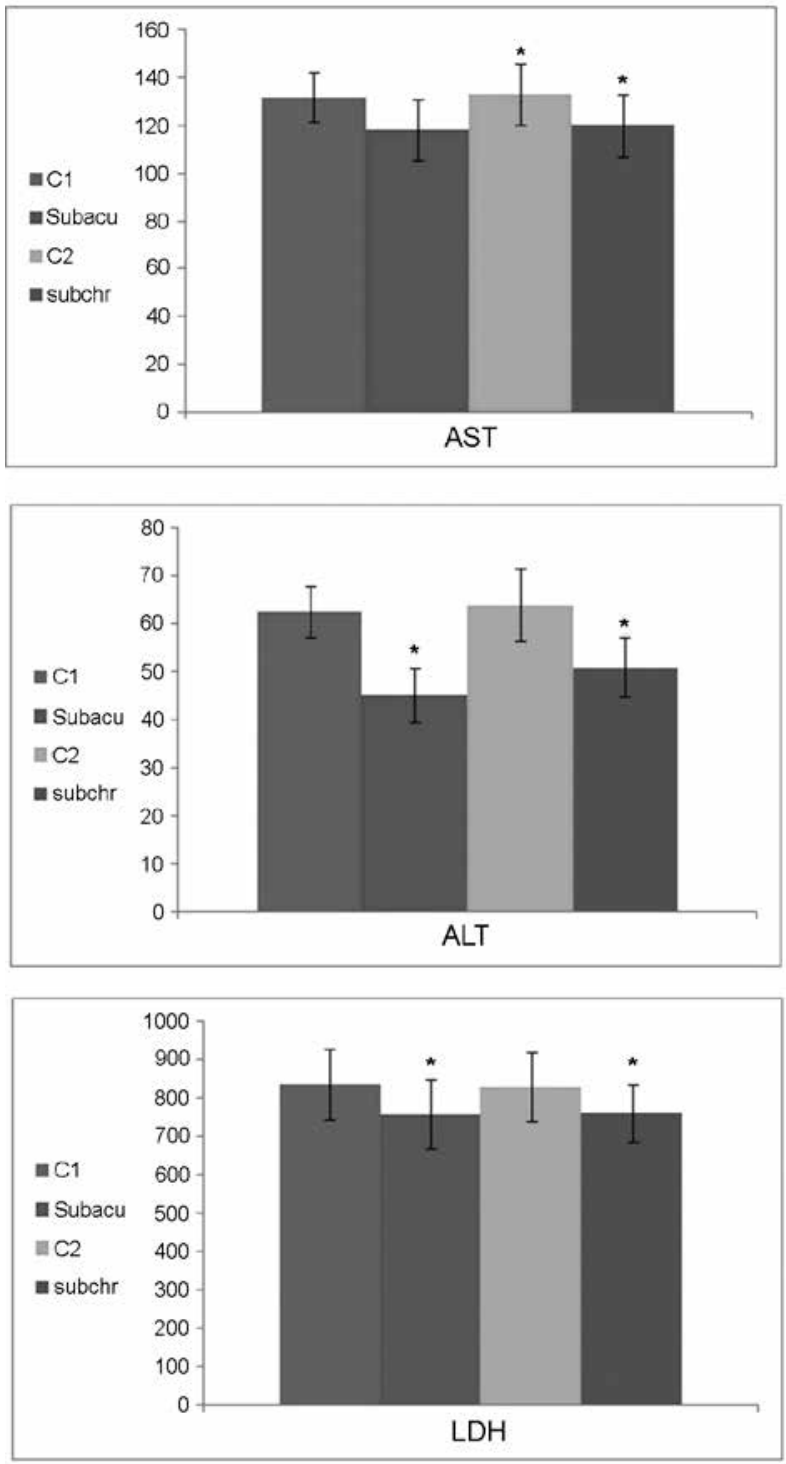

Fig. 3. Effects of iron overload on hepatic function in male albino Wistar rat. Data represent mean $\pm \mathrm{SE}$ serum activities ( $\mathrm{UL}^{-1}$ ) of AST, ALT and LDH of rats intraperitoneally injected with subacute (Subacu, $0.2 \mathrm{mg} \mathrm{kg}^{-1}$ ) and subchronic (subchr, $0.1 \mathrm{mg} \mathrm{kg}^{-1}$ ) overdoses of ISC for 2 and 4 weeks, respectively. C1 and $\mathrm{C} 2$ refer to corresponding controls for subacute and subchronic groups, respectively. Asterisks indicate significant $(* \mathrm{p}>0.05)$ differences from control values 
Table 3

Effects of iron overload on the indices ALT/LDH and AST/ALT in male albino Wistar rat

\begin{tabular}{|c|c|c|c|c|}
\hline & $\mathrm{C} 1$ & Subacute & $\mathrm{C} 2$ & Subchronic \\
\hline ALT-LDH index & 0.075 & 0.057 & 0.077 & 0.067 \\
\hline AST-ALT index & 2.067 & 2.617 & 2.081 & 2.726 \\
\hline
\end{tabular}

Data represent the ratios ALT/LDH and AST/ALT in rats intraperitoneally-injected with subacute $\left(0.2 \mathrm{mg} \mathrm{kg}^{-1}\right)$ and subchronic $\left(0.1 \mathrm{mg} \mathrm{kg}^{-1}\right)$ overdoses of ISC for 2 and 4 weeks, respectively. $\mathrm{C} 1$ and $\mathrm{C} 2$ refer to corresponding controls for subacute and subchronic groups, respectively.

\section{DISCUSSION}

\section{Erythropoiesis and iron status}

Evidence for iron toxicity of the liver is presented by the remarkable elevation of $\mathrm{Fe}$ concentration in the liver tissue, observed following subacute $(3.5$-fold $)(p>0.01)$ and subchronic (6.2-fold) ( $\mathrm{p}>0.001)$ iron application (Table 1). Clinical proof of liver iron toxicity was similarly shown as a 4.5 -fold increase in liver iron stores in humans receiving intramuscular iron dextran injections [28]. The basic hypothesis behind this is the lack of regulating mechanisms of iron excretion from the circulation and the unlikelihood of a spontaneous removal of excess iron. Essentially all circulating plasma iron is bound to transferrin [6]. Although at least eighty percent of the iron bound to circulating transferrin is delivered to the bone marrow and incorporated into newly formed erythrocytes, the liver is one of the major other sites of iron delivery [6]. In the current intraperitoneal polysaccharide preparations, elemental iron is unlikely to join directly the transferrin pool [9] as in case of dietary iron. Ironpolysaccharide complexes might undergo phagocytosis by macrophages, which process iron, clear it from the polysaccharide cage and export it to the circulation for binding to transferrin or store it within ferritin [22]. Although iron recycling by macrophages is one of the least well-understood areas of iron metabolism, there are reports suggesting that iron-laden macrophages may spill over excessive iron to hepatocytes [5].

The drop in UIBC and TIBC attended by the rise in \% transferrin saturation and liver and serum iron is coincident with the onset of lipid peroxidation and oxidative stress shown in an integral part of this experiment [1]. This could indicate that the ability of transferrin to safely bind serum iron is impaired, not only because the iron stores are elevated and there is limited capacity for transferrin molecules to accept additional iron, but also because, as an acute-phase reactant, transferrin activity could be altered in the presence of chemical stress [23].

As expected, all studied indices of the red blood cell count (RBCs, HCT, Hb and WBC) of both subacute or subchronic Fe-overdosed rats exhibited a significant $(p>0.05)$ rise versus corresponding control values. In parenteral iron application, iron-carbohydrate agents mix with plasma before entering the reticuloendothelial 
system, where resident phagocytes of the liver, spleen, and bone marrow remove iron agent from the circulating plasma [14]. Within phagocytes, iron is released from the iron-carbohydrate compound into a low molecular weight iron pool, whence iron is either incorporated by ferritin into intracellular iron stores or is released from the cell to be taken up by the extracellular iron-binding protein transferrin. Transferrin delivers iron to transferrin receptors on the surface of erythroid precursors, and the resulting internalization of the iron-transferrin-transferrin receptor complex supplies iron for hemoglobin synthesis and maturation of red cell [10], hence elevating red blood cell indices.

The more pronounced leukocytosis in subacute (140\%) than in subchronic (114\%) setting versus control might be mediated by the co-ordinated actions of cytokines/ chemokines [11] in response to iron-induced oxidative stress [1] (see Table 2). Excessive iron status was earlier shown to be associated with an increase in cytokine/ chemokine in hepatic acini in rats [11], eventually leading to several events like increased release of leukocytes from bone marrow pools, decreased margination of leukocytes onto vessel walls, decreased extravasation of leukocytes from the vessels into tissues and increased number of precursor cells in the marrow [18]. This ironinduced leukocytosis, along with the decline in TIBC "the surrogate marker of transferrin activity" could, respectively, mark positive and negative acute phase reactions.

\section{Organ function and metabolic stress}

Because serum aminotransferase levels are commonly used to screen for liver disease, recognition of liver damage may be hampered by the reduction in aminotransferase values. Although the biological significance of this decrease in rodents is unclear, Waner and Nyska [32] concluded that until the mechanism of effect of a particular drug or chemical is understood, reduced aminotransferase activities should not be ignored or side-stepped as being within the normal range or of no biological significance. Even though studies aimed to clarify the pathogenesis of this phenomenon are in progress, potential causes of decreased serum activities of ALT, AST and LDH are reported to include decreased hepatocellular production or release of the enzymes, inhibition or reduction of the enzymes activity and/or congestion in the hepatic centrolobular area [31].

Taken together, the two common ratios AST-ALT and ALT-LDH might reflect stress-related tissue damage in subacutely and subchronically iron-overdosed rats, where the former index increased and the latter decreased in both rat groups (Table 3). According to Sánchez et al. [25] increased AST-ALT ratio was diagnostic of tissue injury induced by acute stress in mice, while the rise in the index ALT-LDH was found significant for the prognosis of acute liver injury [20].

Data of the present study indicate a significant $(p>0.05)$ increase in serum concentrations of CORT in both Fe-subacutely and subchronically treated rats versus control subjects. This rise could point out an adaptive response helping the animal to cope with the stressful physiological episode of iron overload until it subsides via a nega- 
tive feedback mechanism. Vertebrates normally respond to the onset of an acute stressor with an acute increase in plasma glucocorticoids [26]. The suggested mechanism implies activation of the hypothalamus-pituitary-adrenal axis by the iron overload stressful condition leading to the release of the glucocorticoid CORT from the adrenal cortex into the blood [13] where it crosses the blood brain barrier and regulates its own release via negative feedback acting on glucocorticoid receptors in the hypothalamus [13].

A potentially important physiological response to stress may be alteration in the gross regulation of energy metabolism. Although hyperlactatemia is frequently used to diagnose inadequate tissue oxygenation, other processes not related to tissue oxygenation may increase lactate levels. The current hyperlactatemia mostly refers to lactate potential to serve as a critical buffer allowing glycolysis to accelerate when large additional amounts of energy are rapidly required under circumstances of ironinduced cellular stress [4]. Iron-induced hyperlactatemia could thus be due to impaired lactate clearance rather than hypoxic tissue production of lactate [7].

Lactate is a crucial metabolite in the two main ATP-producing processes, glycolysis and oxidative phosphorylation. Both processes steadily metabolize glucose when conditions are stable with pyruvate as the molecule that links these two reactions. Under stressful conditions, glycolysis can increase by a factor 100 to 1,000 , provided that glucose is present and pyruvate is converted to lactate. Because the rate of glycolysis can increase faster by several orders of magnitude than oxidative phosphorylation, glycolysis can briefly provide far more ATP when most required under stress conditions. Excess pyruvate will rapidly accumulate and is diverted to lactate in order for glycolysis to proceed [4]. It could be concluded that the observed hyperlactatemia is due to decreased anaerobic threshold and premature entering the anaerobic system with accelerated glycolysis that overwhelms lactate utilization and clearance.

\section{ACKNOWLEDGEMENT}

The authors express their appreciation to the "Deanship of Scientific Research", King Saud University, for funding this work through the research group Project No. RGP-VPP-069.

\section{REFERENCES}

1. Adham, K. G., Alkhalifa, A. A., Farhood, M. H., Al-Eisa, N., Daghestani, M. H. (2014) Oxidative stress and antioxidant response to subacute and subchronic iron overload in Wistar rat. Biologia 69, $817-824$.

2. Al-Dujaili, E. A. S., Hope, J., Estivariz, F. E., Lowry, P. J., Edwards, C. R. W. (1981) Circulating human pituitary pro- $\gamma$-melanotropin enhances the adrenal response to ACTH. Nature, Lond. 291, $156-159$.

3. Babson, A. L., Babson, S. R. (1973) Kinetic colorimetric measurement of serum lactate dehydrogenase activity. Clin. Chem. 19, 766-769.

4. Bakker, J., Nijsten, M. W. N., Jansen, T. C. (2013) Clinical use of lactate monitoring in critically ill patients. Ann. Intensive Care 3, 12.

5. Batts, K. P. (2007) Iron overload syndromes and the liver. Mod. Pathol. 20 (Suppl. 1), S31-S39. 
6. Brissot, P., Ropert, M., Le Lan, C., Loréal, O. (2012) Non-transferrin bound iron: a key role in iron overload and iron toxicity. Rev. Biochim. Biophys. Acta 1820, 403-410.

7. Cairns, S. P. (2006) Lactic acid and exercise performance-culprit or friend? Sports Med. 36, 279-291.

8. Chernecky, C., Berger, B. J. (eds) (2001) Laboratory Tests and Diagnostic Procedures. $3^{\text {rd }}$ ed. Philadelphia, PA, Saunders, pp. 372-376.

9. Daba, A., Gkouvatsos, K., Sebastiani, G., Pantopoulos, K. (2013) Differences in activation of mouse hepcidin by dietary iron and parenterally administered iron dextran: compartmentalization is critical for iron sensing. J. Mol. Med. (Berl) 91, 95-102.

10. Danielson, B. G. (2004) Structure, chemistry, and pharmacokinetics of intravenous iron agents. J. Am Soc. Nephrol. 15, S93-S98.

11. Furze, R. C., Rankin, S. M. (2008) Neutrophil mobilization and clearance in the bone marrow. Immunology 125, 281-288.

12. Golberg, L., Smith, J. P., Martin, L. E. (1957) The effects of intensive and prolonged administration of iron parenterally in animals. Brit. J. exp. Path. 38, 297-311.

13. Herman, J. P., Figueiredo, H., Mueller, N. K., Ulrich-Lai, Y., Ostrander, M. M., Choi, D. C., Cullinan, W. E. (2003) Central mechanisms of stress integration: hierarchical circuitry controlling hypothalamo-pituitary-adrenocortical responsiveness. Front. Neuroendocrinol. 24, 151-180.

14. Hillman, R. S., Ault, K. A., Rinder, H. M. (2005) Hematology in clinical practice: A guide to diagnosis and management. 4th ed., McGraw-Hill Professional, New York, NY.

15. IACUC (Institutional Animal Care and Use Committee) (2008) Use of animals in research, testing and teaching (IACUC, 412-383-2008), IACUC has listed all policies governing use of animals on its website: www.iacuc.pitt.edu/policies.asp.

16. ICSH (International Committee for Standardization in Haematology) (1978) Recommendations for measurement of serum iron in human blood. Br. J. Haematol. 38, 291-294.

17. ICSH (International Committee for Standardization in Haematology) (1978) The measurement of total and unsaturated iron-binding capacity in serum. Br. J. Haematol. 38, 281-297.

18. Jandl, J. H. (1996) Hereditary hemochromatosis. Blood: Textbook of Hematology, Lippincott Williams and Wilkins. Philadelphia.

19. Kingston, H. M., Haswell, S. (eds) (1997) Microwave Enhanced Chemistry. ACS Professional Reference Book Series; American Chemical Society, Washington, DC.

20. Kotoh, K., Enjoji, M., Kato, M., Kohjima, M., Nakamuta, M., Takayanagi, R. (2008) A new parameter using serum lactate dehydrogenase and alanine aminotransferase level is useful for predicting the prognosis of patients at an early stage of acute liver injury: a retrospective study. Comp. Hepatol. 7,6 .

21. Moberg, G. P., Mench, J. A. (2000) The biology of animal stress. Basic principles and implications for animal welfare, CABI Publishing, CAB International. Wallingford, Oxon OX 10 8DE, UK.

22. Muir, A. R., Goldberg, L. (1961) Observations on subcutaneous macrophages. Phagocytosis of irondextran and ferritin synthesis. Quart. J. exp. Physiol. 46, 289-298.

23. Muñoz, M., García-Erce, J. A., Remacha, Á. F. (2011) Disorders of iron metabolism. Part II: iron deficiency and iron overload. J. Clin. Pathol. 64, 287-296.

24. Reitman, S., Frankel, S. (1957) A colorimetric method for the determination of serum glutamic oxalacetic and glutamic pyruvic transaminases. Amer. J. Clin. Pathol. 28, 56-63.

25. Sánchez, O., Arnau, A., Pareja, M., Poch, E., Ramírez, I., Soley, M. (2002) Acute stress-induced tissue injury in mice: differences between emotional and social stress. Cell Stress Chaperon. 7, 36-46.

26. Sapolsky, R. M., Romero, L. M., Munck, A. U. (2000) How do glucocorticoids influence stress responses? Integrating permissive, suppressive, stimulatory, and preparative actions. Endocr. Rev. 21, 55-89.

27. Seasholtz, A. (2000) Regulation of adrenocorticotropic hormone secretion: lessons from mice deficient in corticotrophin-releasing hormone. J. Clin. Invest. 105, 1187-1188.

28. Tavill, A. S., Bipin, K. S., Bacon, B. R. (1990) Iron and the liver: genetic hemochromatosis and other hepatic iron overload disorders. Prog. Liver Dis. 9, 281-305. 
29. Toblli, J. E., Cao, G., Oliveri, L., Angerosa, M. (2011) Evaluation of toxicity and oxidative stress induced by intravenous iron isomaltoside 1000 in a nonclinical model. Drug Res. 61, 553-565.

30. van Herck, H., Baumans, V., Brandt, C. J. W. M., Boere, H. A. G., Hesp, A. P. M., van Lith, H. A., Schurink, M., Beynen, A. C. (2001) Blood sampling from the retro-orbital plexus, the saphenous vein and the tail vein in rats: comparative effects on selected behavioural and blood variables. Lab. Anim $35,131-139$.

31. Vinchi, F., Gastaldi, S., Silengo, L., Altruda, F., Tolosano, E. (2008) Hemopexin prevents endothelial damage and liver congestion in a mouse model of heme overload. Am. J. Pathol. 173, 289-299.

32. Waner, T., Nyska, A. (1991) The toxicological significance of decreased activities of blood alanine and aspartate aminotransferase. Vet. Res. Commun. 15, 73-78.

33. Welz, B., Sperling, M. (1999) Atomic absorption spectrometry, $3^{\text {rd }}$ edition. Wiley-VcH, Weinheim, Germany. 